\title{
RESENHAS
}

DOI http://dx.doi.org/10.1590/1678-49442016v22n2p587

BISPO, Raphael. 2016. Rainhas do rebolado. Carreiras artísticas e sensibilidades femininas no mundo televisivo. Rio de Janeiro: Mauad/Faperj.

\section{Carolina Castellitti}

Programa de Pós-graduação em Antropologia Social do Museu Nacional, Universidade Federal do Rio de Janeiro, Rio de Janeiro/RJ, Brasil

O livro Rainhas do Rebolado analisa a trajetória das chamadas "chacretes", mulheres de camadas populares que se destacaram no cenário televisivo brasileiro entre os anos 1960-70 como assistentes de palco do famoso "Chacrinha" apelido com que ficou conhecido o apresentador Abelardo Barbosa - primeiro show man a se valer do recurso de exibir belas, jovens e sensuais dançarinas em seus programas de auditório, de enorme sucesso entre as décadas de 1950 e 1980. Desde uma "perspectiva multifacetada", a etnografia integra a análise de revistas, fotografias, material jornalístico e, principalmente, da intensa convivência do autor com algumas dessas mulheres entre 2009 e 2011. Vem se constituir, assim, em um estudo antropológico rigoroso e extremamente sensível, desde sua concepção como prática etnográfica até seu produto final em forma de texto. Em um contexto de debate e recente aprovação da nova minuta sobre ética em pesquisas nas Ciências Humanas e Sociais, este livro é uma demonstração exemplar de como é possível levar a cabo uma pesquisa comprometida com o conhecimento do mundo social e que, ao mesmo tempo, respeite a dignidade, a liberdade e a autonomia dos sujeitos envolvidos no processo. A presença de algumas das protagonistas na apresentação do livro, para honrar o autor, e por que não, suas próprias carreiras artísticas, constitui mais uma prova das potencialidades de uma prática científica responsável e comprometida.

O livro está organizado em três partes, compostas por dois capítulos cada uma. Transitando entre os "Refletores e bastidores" - título da 
primeira parte, acessamos as condições e as vicissitudes da escolha do trabalho de dançarina sensual, considerando que a maioria das mulheres que vieram a fazer parte dessa "primeira geração" de chacretes provinha das camadas populares do Rio de Janeiro. O autor observa como nos processos de seleção certas marcas corporais eram enfatizadas em detrimento de outras: o tamanho das coxas, do quadril e da bunda eram os componentes mais valorizados dos corpos carnudos e sensuais das "boazudas", em oposição a outros traços, como altura e tamanho dos seios. Outros marcadores, como os de cor/raça, operavam segundo lógicas menos óbvias: embora existisse a intenção da direção de representar todas as "cores brasileiras" para agradar a uma maior quantidade de telespectadores, as louras e as mulatas eram as tonalidades mais requisitadas.

O tipo físico das girls, no entanto, era tão importante quanto certo modo de se portar em frente às câmeras, pois através dele deveriam evocar constantemente a imagem de mulher superexcitada e sempre disponível. A partir desta observação e em diálogo com autoras imprescindíveis para os estudos de gênero como Judith Butler e Joan Scott, Bispo constrói a criativa noção de performance de superfêmea: uma dramatização da feminilidade que, através do exagero, faz as dançarinas parecerem "mais mulheres do que qualquer outra mulher". A descrição atenta e detalhada é enriquecida por meio de um exercício de aproximação e distanciamento com diferentes carreiras do mundo da arte, da televisão e da moda, documentadas em outros trabalhos antropológicos do Brasil e do mundo.

Do palco e das câmeras para fora do set de filmagem, no bas-fond ou no submundo dessa indústria cultural, Bispo aborda um dos assuntos mais complexos em termos do contrato entre pesquisador e pesquisado: as experiências das chacretes com a prostituição. Esta complexidade não emerge tanto do necessário controle dos limites do passível de ser tornado público no relato etnográfico, mas sim do caráter polêmico e explosivo que confissões relativas a essas práticas tiveram entre as próprias chacretes. Mais uma vez, o autor lida bem com essa polêmica, mostrando que fazer programas era uma possibilidade entre outras de obter dinheiro, um "trabalho extra", que nem todas utilizaram e algumas condenavam enfaticamente. Do mesmo modo, em diálogo com pesquisas clássicas da antropologia brasileira sobre prostituição, chamar a atenção para o prazer que as chacretes tinham por se sentirem desejadas por homens poderosos permite ao autor matizar a interpretação da prostituição como "estratégia de sobrevivência" sem abrir mão de se pensar o valor econômico dessa atividade. 
Na segunda parte do livro, Bispo enfrenta diretamente o conflito de moralidades - daí o título da seção: "É bom para o Moral?" - evidenciado também, mas não exclusivamente, na mencionada polêmica em torno da prostituição. Através das histórias de vida de Índia Potira e Edilma Campos e, em especial, dos seus tipos de narrativas, entendidas como uma construção da autoimagem por meio da negociação com o outro (neste caso, o pesquisador), o autor destrincha um embate de feminilidades em que ambas as narrativas se apresentam como os polos de um continuum. Tecendo os fios dos esquecimentos e das lembranças, das expectativas e das frustrações, o autor traz o juízo da fama para problematizar a honra feminina popular urbana no contexto do star system, principalmente em relação à moral afetivo-sexual. Por meio de postais etnográficos dos mais tradicionais e decadentes bares da Lapa ou dos afastados e pouco acessíveis segmentos mais pobres do Recreio dos Bandeirantes, conhecemos detalhes das vidas dessas mulheres, passando pelo auge e o declínio de suas carreiras artísticas até chegarmos ao momento atual.

Mais para o final desta segunda parte, o autor propõe a noção de imaginação grotesca para sistematizar algumas observações sobre essa particular configuração de narrativas, emoções e subjetividades. Trata-se de um tipo de discurso em que o importante na narração sobre si mesmo são as experiências mais exóticas e fora de sentido, que garantem uma singularização e uma sensação de "estranheza" em relação ao cotidiano. Nesta direção, desde uma perspectiva situacional e levando em conta a interseção entre marcadores sociais como raça, família, gênero e idade, Bispo aponta distintos graus e modos de agência feminina nas experiências das chacretes. Assumindo uma posição no debate antropológico sobre a problemática do individualismo no contexto das camadas populares urbanas, o autor reconhece que "virar artista" constitui um período de independência com potencial de "autoafirmação" que não pode, no entanto, ser classificado como exemplo de individualismo. Isto porque tal processo de "autoafirmação" remete a uma "melhoria de vida" garantida pelo mundo artístico, que não se traduz num rompimento com o grupo e a moral familiar.

No capítulo cinco, já na terceira e última parte do livro, o autor embarca na instigante tarefa de realizar uma etnografia da solidão, a partir das experiências de sofrimento e de "perturbação" das chacretes na contemporaneidade. Por ter conseguido tecer uma relação de proximidade com algumas dessas mulheres, passando a frequentar suas casas e acompanhando-as em suas atividades cotidianas, essa etnografia da contemporaneidade das chacretes 
ganha em profundidade e multiplicidade de abordagens, e amplia seus horizontes comparativos por meio do diálogo com a tradição de estudos antropológicos sobre velhice no Brasil. O recurso metodológico do capítulo também é instigante. Constroem-se três retratos da solidão, com base em três trajetórias de vida narradas a partir de formas diferenciadas de expressar esse sentimento: a confissão, a queixa e o silêncio. A relação com o núcleo familiar de origem, os amores que se foram, a maternidade e os sentidos que todos esses eventos assumem para explicar a situação atual de solidão segundo um modo específico de gestão do passado são reconstruídos com esperteza pelo autor, chamando a atenção para a cadência e o tom, as ênfases, as repetições e as ausências nessas narrativas.

O capítulo final do "Crepúsculo das deusas" (terceira parte do livro) recupera as tensões dessas narrativas como marcas da maneira de lidar com a passagem do tempo nas sociedades contemporâneas. Reconhecer alguns sinais da idade como inevitáveis (saúde, capacidade física e estética) e outros como relativos (a juventude do "espírito" ou da "alma", que não corresponde à idade) faz parte dessa tensão. Ao mesmo tempo, um controle do corpo em que certa feminilidade e "tensão erótica" devem estar sempre presentes (inclusive para as chacretes evangélicas) convive com uma va- lorização da "naturalidade" desse corpo, na juventude (à diferença das novas dançarinas que, segundo elas, modificam excessivamente seus corpos) e na velhice. A valorização da naturalidade dos corpos também se mostra no orgulho de se ter uma vida sexual ativa. No entanto, os constrangimentos derivados do discurso sobre o sexo pleno e feliz na velhice se fazem presentes no sentimento de culpa por não ter marido e na dificuldade em conseguir um parceiro sexual que as satisfaça. Nesta dimensão, e em outras como a do atual apelo midiático das "boazudas da terceira idade", no caráter paralelamente transgressor e conservador das danças eróticas, o autor transita habilmente entre os riscos e as oportunidades, as "opressões" e as possibilidades de agência que tais experiências apresentam para os sujeitos que as vivenciam.

Rainhas do rebolado tem tudo para se consolidar como uma obra de referência nas ciências sociais, pelo menos para as pesquisas dedicadas ao estudo das classes populares e das carreiras no mundo do espetáculo: desenho metodológico rigoroso e responsável, informação empírica original e criatividade teórica. Embora a elucubração teórica não constitua o objetivo primordial do trabalho, o autor faz um uso inteligente e produtivo de conceitos propostos por autores reconhecidos das ciências sociais, como Howard Becker e Erving Goffman, e dos 
estudos de gênero e sexualidade, como Michel Foucault, Judith Butler e Teresa de Lauretis. Paralelamente, transita com facilidade pelo enorme corpus de pesquisa acumulado no campo da antropologia urbana brasileira, em áreas como sexualidade, carreira, envelhecimento e emoções. Nesse intenso diálogo, Bispo constrói criativas categorias, como performance de superfêmea, juízo da fama e imaginação grotesca, que prometem rendimentos importantes se usadas e discutidas junto a informações provenientes de outros investimentos etnográficos.

DOI http://dx.doi.org/10.1590/1678-49442016v22n2p591 WATEAU, Fabienne. 2014. "Querem fazer um mar...". Ensaio sobre a barragem de Alqueva e a aldeia submersa da Luz. Lisboa: Imprensa de Ciências Sociais. 184pp.

\section{André Dumans Guedes}

Universidade Federal Fluminense, Niterói/ RJ, Brasil

Pensado à luz dos debates políticos e acadêmicos relativos às barragens no Brasil, "Querem fazer um mar", livro da pesquisadora francesa Fabienne Wateau, oferece certamente um desvio de perspectiva interessante. É esta chave comparativa, portanto, o que orienta esta resenha.

Wateau é pesquisadora do Centre National de la Recherche
Scientifique (CNRS) e professora na Universidade de Paris Ouest Nanterre la Défense e no Museu do Quai Branly, também em Paris. Ela trabalha há mais de 20 anos em Portugal, investigando os conflitos e as políticas em torno da gestão da água e buscando considerar estes últimos a partir dos processos e das interfaces que articulam suas dimensões locais, nacionais e globais. É no contexto de tal trajetória que emerge a obra em questão, fruto de uma colaboração de Wateau com o Instituto de Ciências Sociais da Universidade de Lisboa - órgão que é responsável também pela publicação do livro. Aí, ela examina como a construção da barragem de Alqueva - realizada na virada deste século, no rio Minho, em Portugal - levou ao alagamento e à reconstrução, num outro lugar, de uma pequena aldeia de camponeses.

Para o exame desta situação, a autora dividiu o livro em seis partes, cada uma delas se desenvolvendo a partir de um registro narrativo distinto. Esta diversidade é tematizada já no prefácio, cujo título - "Escrita e Antropologia" - sinaliza a preocupação de Wateau em fazer do livro "uma empresa experimental, uma outra forma de escrever antropologia" (:21). Pode-se argumentar que nesta disciplina tais esforços experimentais não são tão incomuns como sugerido. De qualquer forma, no que diz respeito ao tema das barragens, 